\title{
BOOKTUBERS E A INFLUÊNCIA LTERÁRIAH UW ESTUDO DE CASO DO VLOG DA JU CIRQUEIRA
}

\author{
BOOKTUBERS AND THE LITERACY INFLUENCE: \\ A CASE STUDY FROM JU CIRQUEIRA VLOG
}

\section{Pâmela da Silva Pochmann}

Especialista em Teoria e Prática na Formação do Leitor pela Universidade Estadual do Rio Grande do Sul (Porto Alegre/Brasil). Atua como relações-públicas na Universidade Federal do Rio Grande do Sul (Porto Alegre/Brasil).

E-mail: pamelapochmann@gmail.com

ORCID: http://orcid.org/0000-0001-7177-3869

\section{Magali de Moraes Menti}

Doutora em Letras/Linguística Aplicada pela Universidade Federal do Rio Grande do Sul (Porto Alegre/Brasil). Professora adjunta da

Universidade Estadual do Rio Grande do Sul (Porto Alegre/Brasil). Coordenadora institucional do Programa Inglês Sem Fronteiras - Nucli

- Ensino de Línguas Estrangeiras - pela Universidade Estadual do Rio Grande do Sul (Porto Alegre/Brasil).

E-mail: magali@lingua.com.br

ORCID: http://orcid.org/0000-0003-4698-2794

Recebido em: 26 de março de 2020

Aprovado em: 6 de julho de 2020

Sistema de Avaliação: Double Blind Review RPR |a. 17 | n. 3 |p. 25-43| set./dez. 2020

DOI: https://doi.org/10.25112/rpr.v3i0.2073 


\section{RESUMO}

Este estudo teve como problema de pesquisa verificar como blogs/vlogs literários, enquanto meios de comunicação, podem influenciar a escolha leitora. Para isso, selecionou-se o vlog da Ju Cirqueira, blogueira do blog Nuvem Literária, para um estudo de caso. 0 objetivo geral foi identificar quais estratégias a blogueira utiliza que podem influenciar na escolha literária dos seus seguidores a partir de suas publicações/vídeos. Os objetivos específicos foram verificar as estratégias que a blogueira utiliza para transmitir suas mensagens e criar conexões, e se utiliza algum padrão em seus vídeos. Para tanto, abordou-se questões relacionadas à leitura, texto, práticas de leitura, formação de leitores e ato comunicativo. Os procedimentos metodológicos abrangeram uma parte quantitativa, em que foram destacados números de blogs existentes, perfil dos usuários e categorias de blogs, e uma parte qualitativa em que, por meio de categorização de análise proposta por Jeffman (2015) e de análise de conteúdo, examinou-se dez vídeos do canal da Ju Cirqueira. A partir dos dados coletados, pode-se ter uma amostragem de como são os blogs no Brasil, o perfil do público leitor de blogs e vlogs e características que fazem com que os booktubers fidelizem seus seguidores e, consequentemente, apresentem novas opções de leitura. Entre os padrões utilizados pela blogueira destacam-se a cultura do quarto, as estratégias de comunicação e a cultura de participação.

Palavras-chave: Booktubers. Influência literária. Ju Cirqueira. Vlog. Formação do Leitor.

\section{ABSTRACT}

This study aimed to verify how literary blogs/vlogs, as a means of communication, can influence te choice for reading. To this end, the vlog by Ju Cirqueira, blogger of the blog Nuvem Literária, was chosen for a case study. The goal of the survey was to look at how the blogger influences the literary choice of her followers, what strategies she uses to broadcast her messages and make connections, and whether she uses some pattern in her videos. The focus of the analysis was on concepts pertaining to reading, the text, reading practices, reader training and mass media. There were quantitative methodological procedures in which numbers of existing blogs, profile of users and categories of blogs were sought; followed by qualitative procedures carried out through categories of analysis and content analysis to look for patterns in ten videos of the channel of Ju Cirqueira. From the data collected, one can have a sampling of how blogs are in Brazil, the profile of the public readers of blogs and vlogs and characteristics that make booktubers loyal to their followers and, consequently, present new reading options. Among the different languages used in communication, we highlight the culture of the room, the communication strategies and the culture of participation.

Keywords: Booktubers. Literacy influence. Ju Cirqueira. Literary Vlog. Formation of the reader. 


\section{INTRODUÇÃO}

A leitura está presente em todos os momentos da vida, seja enquanto lê-se signos verbais, ou enquanto interpreta-se um contexto, ou ainda quando se utiliza o conhecimento de mundo e a intertextualidade para compreender sentidos. A leitura não se restringe às palavras, ela está presente nos desenhos, nas imagens, nas falas, nos contextos e também no que não está sendo dito. Por isso, a importância de estudá-la em profundidade: leitura e linguagem são formas de comunicação, de poder e de significação (KOCH; ELIAS, 2008).

Entre outros saberes, saber ler em um mundo letrado, como o atual, tornou-se uma necessidade, uma questão de sobrevivência, já que a leitura está presente em diversos ambientes e promove a conectividade entre as pessoas. Uma das formas de promover a conexão entre os indivíduos hoje são as Tecnologias da Informação e Comunicação (TICs), que são os meios pelos quais as informações são transmitidas. Para Oliveira e colaboradores (2015, p. 78), as TICs são "um conjunto de recursos tecnológicos integrados entre si, que proporcionam por meio das funções de software e telecomunicações, a automação e comunicação dos processos de negócios, da pesquisa científica e de ensino e aprendizagem".

Sousa e colaboradores (2007) afirmam que, com o avanço das tecnologias digitais, cada vez mais as pessoas estão utilizando-se das mídias e plataformas digitas no seu dia a dia. Observa-se que as pessoas posicionam-se e discutem mais suas opiniões nestes ambientes virtuais.

Uma das mídias do ambiente virtual é o blog. Para Karhawi (2018), a blogosfera hoje é considerada uma mídia, um veículo de comunicação, um espaço de comunicação - gerenciado não apenas por blogueiros, mas por comunicadores -, uma fonte de renda, que é credenciada pelos leitores e pelos próprios blogs.

A partir disso, optou-se por analisar uma categoria específica de blogs/vlogs: os literários, especificamente o blog/vlog Nuvem Literária por meio de sua blogueira Ju Cirqueira. O problema de pesquisa foi verificar como blogs e vlogs literários, enquanto ferramentas de comunicação de massa, podem influenciar nas escolhas de seus leitores. 0 objetivo geral da pesquisa foi identificar quais estratégias a blogueira utiliza que podem influenciar na escolha literária dos seus seguidores a partir de suas publicações/vídeos, e os objetivos específicos foram perceber o padrão utilizado pela blogueira em seus vídeos; quais estratégias ela utiliza para "vender" o livro; e como ocorre a interação da blogueira com seus seguidores. A análise foi realizada de forma qualitativa - por meio de critérios de análise apresentados por Jeffman (2015): cultura de quarto, cultura de participação, cultura oral e estratégias de conexões - e quantitativa - apresentação dos blogs e seu universo. 


\section{A LEITURA E O ATO COMUNICATIVO}

$O$ ato de ler e o que significa a leitura estão intrinsecamente relacionados à escrita e à fala. Os variados conceitos encontrados na revisão bibliográfica dependem da concepção do autor/pesquisador como sujeito, como as suas experiências de vida o conduziram à sua formação como leitor. Sendo assim, o conceito de leitura é abrangente e envolve a leitura de mundo, estando este sujeito em um contexto, passivo ou ativo, conforme sua experiência contribuiu e estruturou sua concepção e percepção do que significa ler. Para Koch e Elias (2006), dependem das concepções de sujeito, de língua, de texto e de sentido que se empregue em determinado contexto.

A concepção de leitura foi modificando-se ao longo dos anos e hoje é vista dialogicamente: os leitores não são mais passivos, e sim atores que constroem e são construídos pelo texto, como afirmam Koch e Elias (2006). Outro fator que impactou diretamente a leitura foi a forma de ler e os meios em que essa leitura é transmitida. Portanto, a leitura adapta-se ao seu contexto e está continuamente ligada à história. Corroborando com essa visão, Orlandi $(1996$, p. 9) destaca que "a leitura [...] é uma questão de natureza, de condições, de modos de relação, de trabalho, de produção de sentidos, em uma palavra: de historicidade".

Para Orlandi (1996, p. 7), a leitura é "atribuição de sentidos, concepção e leitura de mundo". Compreende-se, assim, que a leitura produz seres humanos mais críticos e capazes de cumprir com sua função social. Outra questão que influencia diretamente na leitura dos textos é a forma como cada leitor o interpreta, como afirma Nascimento (2018, p. 195), essa mecânica não ocorre do mesmo modo: "a distância é grande entre os letrados de talento e os leitores menos hábeis que não dispõem das mesmas bases intelectuais ou a mesma reação com o escrito".

Para Canclini (2008, p. 51), "os textos e as imagens vão existindo à medida que o leitor ou o espectador os usam ou reinterpretam". Sendo assim, para que exista um texto é necessário que exista um leitor e, dessa forma, "todo texto prevê seu leitor e não pode abrir mão dele" (CANCLINI, 2008, p. 51). Lois (2010, p. 31) afirma que "hoje, se reconhece o texto como uma fonte de estímulo e a leitura como um processo de formação do sentido. $O$ autor 'perde' a posse do texto na medida em que esse texto se dispõe ao olhar do outro".

Egiert e Mello (2013) reconhecem o leitor como um sujeito ativo na construção do conhecimento e a leitura como uma prática social. Sendo assim, percebe-se que cada vez mais o leitor tem posição de destaque e é construtor das histórias, juntamente com o autor. $\mathrm{O}$ fato de o leitor poder construir o que lê e atribuir significados diversos do pensado pelo autor contribui ainda mais para o enriquecimento das histórias. Para Lajolo (1993) o leitor tem um distanciamento da obra ao iniciar uma leitura, portanto está 
aberto às surpresas, ao diálogo. Já o autor, lê com os olhos viciados, afinal ele está de acordo com aquilo que escreve.

Um acontecimento que colaborou com a mudança do papel dos leitores é o uso da internet. A internet possibilitou mais interação e proximidade autor-leitor, dando a "ilusão de contato 'direto' e 'real', recobrindo as mediações realizadas" (BIRMAN, 2013, p. 9). Nesse contexto, autor e leitor ficam mais próximos e dialogam entre si, em muitos casos, construindo juntos histórias e enredos.

Com o surgimento de novas formas de "aprender a leitura" e com o advento das tecnologias da informação, outras práticas tornaram-se utilizáveis, do ponto de vista educacional. Como ressalta Silva (2015), o uso acadêmico das novas tecnologias está em um amplo debate.

Para Lois (2010, p. 20), "leitura e escrita nasceram de um processo tecnológico" e, sendo assim, por meio da evolução humana, técnica de comunicação. As novas tecnologias da informação também surgiram por meio das inovações e pela necessidade de novas formas de se comunicar. A tecnologia tem papel fundamental no avanço e desenvolvimento de todas as áreas de conhecimento, além disso, é uma nova forma de linguagem e de leitura (LOIS, 2010).

A partir da leitura ativa e da construção de sentidos por um leitor vital ${ }^{1}$, como afirma Assumção (2009), é possível que o leitor tenha outra percepção do contexto ao seu redor. Krug (2015, p. 1) ressalta que a leitura é responsável por contribuir com a formação do indivíduo, "influenciando-o a analisar a sociedade, seu dia a dia e, de modo particular, ampliando e diversificando visões e interpretações sobre o mundo, com relação à vida em si mesma".

Para Lima e Silva (2012), o ciberespaço caracteriza-se como uma ferramenta capaz de influenciar na formação de leitores por utilizar vários contextos de linguagem, escrita, interação, gêneros e textos. A estrutura do texto virtual é, em alguns casos, diferente das que foram escritas manualmente e por meio desse ambiente é possível navegar por vários gêneros e acessar links que levam a outros textos (LIMA; SILVA, 2012), caracterizando bem a intertextualidade².

No ciberespaço percebe-se que a comunicação interpessoal e o ato comunicativo são concebidos por sujeitos, que ora falam e ora interpretam, como afirma $\operatorname{Motta}^{3}$ (2003, p. 8):

\footnotetext{
${ }^{1} \mathrm{O}$ autor apresenta o conceito 'Leitor vital' como aquele que dá sentido ao texto, que lê, o interpreta e conecta com os seus conhecimentos e com o contexto em que está inserido.

2 Para Koch e Elias (2006, p. 86) a "intertextualidade ocorre quando, em um texto, está inserido outro texto (intertexto) anteriormente produzido, que faz parte da memória social de uma coletividade".

${ }^{3} \mathrm{O}$ autor trata especificamente em seus estudos sobre o jornalismo público, mas entendemos que os conceitos apresentados enquadram-se nas abordagens teóricas aqui propostas.
} 
Todo ato comunicativo é um processo dinâmico, um jogo dialético de criação de sentidos entre um sujeito emissor e um sujeito destinatário. Um princípio de contrários, um jogo entre efeitos pretendidos e resultados logrados. Um jogo entre aquilo que o emissor diz explicitamente, além das intencionalidades implícitas no seu ato de fala, por um lado, e as interpretações lineares e as reinterpretações criativas que o receptor destinatário leva a cabo no seu ato de leitura, por outro lado.

Sendo assim, a interpretação é algo muito subjetivo que depende do contexto e dos sujeitos envolvidos. Para Baldissera (2001, p. 3), "deve-se atentar para o fato de que os sentidos, disponíveis na cadeia de comunicação, sempre serão construídos e disputados por sujeitos interlocutores, a partir do seu saber prévio". Desta forma, a comunicação é a união de saberes e de sentidos construídos a partir do conhecimento prévio dos sujeitos envolvidos. Outra condição que pode atingir o processo comunicativo são as estratégias de comunicação, descritas por Baldissera (2001, p. 3) como "o modo como os emissores/receptores constroem e dispõem efeitos de sentido na cadeia de comunicação".

Baldissera (2001, p. 3) destaca ainda que a comunicação é o processo de construção e disputa de sentidos e, por isso, nessa relação, os indivíduos "estabelecem 'relações de força' suportadas em informações e saberes que permitem a utilização de estratégias de comunicação, com o objetivo de direcionar ou manipular a individualização dos sentidos". Portanto, compreende-se que as estratégias de comunicação são as formas que os interlocutores utilizam para persuadir seus receptores, objetivando passar determinada informação.

\section{AS TECNOLOGIAS DIGITAIS DA INFORMAÇÃO E COMUNICAÇÃO}

Com o advento das Tecnologias Digitais da Informação e Comunicação (TDIC), os meios de comunicar modificaram-se, impactando diretamente no cotidiano das pessoas (RIOS; MENDES, 2014). Por meio da internet, as informações são difundidas e qualquer indivíduo que tenha acesso pode consultá-las. Além disso, Rios e Mendes (2014, p. 161) afirmam que as TDIC transformaram a "maneira de comunicar, estudar, trabalhar, de interagir com serviços, minimizando espaços e tempos, ao acessar e receber informações, influenciando, consequentemente, na maneira de agir e pensar".

Entre estas está o blog, que para Primo e Smaniotto (2006) não é apenas um texto, mas um programa e um espaço. Os autores afirmam que os blogs são um espaço em que blogueiros (autores) e internautas

\footnotetext{
${ }^{4}$ Baldissera escreve, principalmente, sobre a comunicação no contexto organizacional, mas compreendemos que os conceitos apresentados pelo autor são essenciais a essa pesquisa.
} 
(leitores) se encontram, utilizando, geralmente, um programa de blog, apesar de existirem outros recursos possiveis para criar uma página de blog. Os autores justificam a ocorrência de não ser apenas um texto, pelo fato deste local não ser restrito ao uso da escrita, a plataforma pode apresentar diversos signos verbais e não verbais (PRIMO; SMANIOTTO, 2006).

Uma das categorias de blogs que está crescendo na web, segundo Santos e colaboradores (2014), é a blogosfera literária. Máximo (2007, p. 30) define blog literário como o "espaço de publicação, divulgação e crítica de criações literárias (do próprio blogueiro ou alheias)". Esse ambiente tem despertado a atenção dos setores de marketing das editoras que buscam os blogueiros para promoções e divulgações de lançamentos de livros (SANTOS et al., 2014). Segundo Santos e colaboradores (2014, p. 102), "as editoras reconhecem nos blogs voltados para literatura um verdadeiro potencial de difusão do conteúdo literário, e muito desse potencial está relacionado com a audiência desse meio de comunicação".

Santos e colaboradores (2014) ressaltam ainda que a grande audiência de blogs literários deve-se à interação que esse espaço proporciona, sendo assim, muito ativa e proporcionando que neste espaço blogueiros estabeleçam relacionamento e diálogo por meio de escrita pessoal, fidelizando seus leitores, que interagem, principalmente, por meio de comentários.

De forma geral, como afirmam os autores, os blogs literários buscam "promover o hábito da leitura e proporcionar um diálogo em torno de livros que vão dos famosos clássicos aos lançamentos modernos" (SANTOS et al., 2014, p. 104). Sendo assim, estabelecem uma conexão, principalmente, com usuários que já são leitores. Apesar disso, por causa da divulgação que os blogueiros usam, estão conseguindo atrair não leitores também.

Neste ambiente surgiu uma nova forma de divulgação literária: os vlogs literários ou booktubers. Para Jeffman (2015), os vlogs literários ou booktubers são canais de vídeos do YouTube, uma comunidade que se dedica ao ramo literário, por meio de divulgação de resenhas, autores e demais atividades literárias. Tais canais exemplificam muito bem a dinâmica de transformação no ato de consumir, além de demonstrar como uma plataforma pode criar conexões.

O YouTube tornou-se uma plataforma de redes e conexões e os booktubers utilizam-se de três estratégias para criar conexões e redes com seus seguidores: o próprio vídeo, o uso de Tags ${ }^{5}$ e os comentários no YouTube. Além disso, a autora diz que os booktubers são "letrados" em YouTube, o que quer dizer que os vloguers "não apenas criam e consomem o conteúdo em vídeo", mas também são

\footnotetext{
5 "As Tags, além de categorizar assuntos para que os usuários e vlogueiros saibam do que se trata o vídeo, também atuam como um dos 'vários modos dos quais a comunidade autoconstituinte do YouTube se utiliza para introduzir táticas para tentar navegar, moldar e controlar a vasta e caótica matriz de conteúdo existente na rede'" (JEFFMAN, 2015, p. 104).
} 
capazes de entender a dinâmica de funcionamento do YouTube enquanto tecnologia e como uma rede social (JEFFMAN, 2015, p. 105).

Sendo assim, os booktubers constroem o que se pode denominar de comunidade virtual com seus seguidores. Recuero (2003, p. 5) define como comunidade virtual o "grupo de pessoas que estabelecem entre si relações sociais, que permanecem um tempo suficiente para que elas possam constituir um corpo organizado, através da comunicação mediada por computador e associada a um virtual settlement ${ }^{\prime \prime}$. Percebe-se que os booktubers construíram essa comunidade consolidada dentro do YouTube e que, como afirma Jeffman (2015), há uma cultura da participação que consiste na relação entre leitores, na exposição dos gostos e opiniões literárias. Observa-se que os vlogs contribuem em muitos aspectos para o desenvolvimento da leitura, da opinião, do compartilhamento e da oralidade. A leitura e as práticas de leituras são apresentadas de diversas formas - como imagens, textos, vídeos. Além da relação autortexto-leitor ser mais próxima e possibilitar interação.

\section{METODOLOGIA}

A pesquisa foi realizada em duas etapas, uma quantitativa e outra qualitativa. A pesquisa quantitativa focou na categorização e identificação do universo dos blogs. A pesquisa qualitativa consistiu de um estudo de caso do blog/vlog da Ju Cirqueira e de análise de conteúdo e de categorização a partir dos conceitos de Jeffman (2015), para, desta forma, compreender-se os sentidos presentes nos textos. A análise ocorreu entre os meses de agosto de 2018 e janeiro de 2019.

Na primeira parte do estudo, a análise quantitativa consistiu em uma pesquisa abrangendo o universo dos blogs. Para isso foram identificados, por meio de artigos, pesquisas e dados já coletados por outros pesquisadores, a quantidade de blogs existentes no Brasil ou um universo estimado numericamente. Para ter-se um melhor conhecimento da abrangência dessa mídia e uma estimativa de público, apresentando seus hábitos, idade, profissão, escolaridade.

Na segunda parte buscou-se referenciar os núcleos de sentidos presentes nos textos, para, então, apresentar o contexto. Para isso, optou-se por uma categorização de análise a partir de conceitos

\footnotetext{
6 "Virtual Settlement é uma proposição de Quentin Jones (1998, online). De acordo com o autor, o virtual settlement é um 'lugar' no ciberespaço ao qual associa-se uma comunidade virtual" (RECUERO, 2003, p. 5).
} 
apresentados por Jeffman (2015): cultura de quarto ${ }^{7}$, cultura de participação ${ }^{8}$, cultura oral ${ }^{9}$ e estratégias de conexões ${ }^{10}$. Para tal, destacou-se o ambiente em que a blogueira estava no momento da filmagem; se há algum parâmetro presente em todos os vídeos, ou seja, se há a padrões nos textos; a relação aos livros apresentados no canal, como a blogueira os apresenta, como menciona sua experiência literária e as experiências ruins; e a relação que a blogueira desenvolve com seus seguidores, por meio das conversas com seus seguidores, como abre espaço para interação, sugestões e críticas.

Analisou-se 10 vídeos do vlogda Ju Cirqueira, por entender-se que com essa quantidade de vídeos seria possível verificar os objetivos propostos para esta análise e abranger ao menos um tipo de categoria de vídeo, como: tags, vlogs, resenhas de livro e com conteúdo patrocinado. Abaixo se destaca as categorias a que pertencem os vídeos escolhidos:

- Resenhas:

- "Terra das mulheres, de Charlotte Perkins Gilman", publicado em 03/10/2018;

- "Eu receberia as piores notícias dos seus lindos lábios, de Marçal Aquino", publicado em 10/10/2018;

- TAG:

- "Tag da discórdia", publicado em 04/11/2018;

- "Livros que na na não", publicado em 04/10/2017;

- Conteúdo patrocinado:

- "O homem de giz, de C. J. Tudor", publicado em 27/03/2018;

- "Primeira caixinha TAG Inéditos | Um Thriller de tirar o fôlego!", publicado em 16/05/2018;

- "A princesa prometida, de William Goldman", publicado em 29/06/2018;

- "Crianças roubadas e corações partidos em Segredos de Família, de Lisa Wingate", publicado em 10/08/2018;

- "Sweeney Todd: O barbeiro demoníaco, de Fleet Street", publicado em 02/11/2018;

- Vlog:

- "Trocando livros no sebo \#Vlog", publicado em 04/07/2018.

\footnotetext{
7 Para Jeffman (2015) a cultura do quarto trata-se da gravação dos vídeos no próprio quarto do vlogueiro, mostrando atrás de si sua estante com livros e adereços. Com a utilização desta estratégia, o vlogueiro traz mais autoridade para a sua fala e aproxima o público que 0 assiste.

${ }^{8}$ A cultura da participação consiste na relação entre leitores, na exposição dos gostos e opiniões literárias (JEFFMAN, 2015).

9 Para Jeffman (2015) os booktubers resgatam a cultura oral ao compartilhar suas opiniões sobre determinada obra. Além de desmistificar a leitura como um ato solitário que envolve apenas leitor e livro, tornando-a uma prática de socialização.

${ }^{10}$ Jeffman (2015) diz que o YouTube tornou-se uma plataforma de redes e conexões, e os booktubers utilizam-se de três estratégias para criar conexões e redes com seus seguidores: o próprio vídeo, o uso de Tags e os comentários no YouTube.
} 


\subsection{BLOG/VLOG NUVEM LITERÁRIA POR JU CIRQUEIRA}

O blog Nuvem Literária foi criado em 2013 por Juliana Cirqueira com o objetivo de ter um espaço para conversar sobre uma das paixões da blogueira: os livros. 0 canal do YouTube, iniciado no mesmo ano, conta, atualmente ${ }^{11}$, com 217 mil inscritos e 12.737.001 visualizações de vídeo.

Juliana tem 29 anos, é formada em Letras - Inglês pela Universidade Federal do Espírito Santo e pósgraduada em Tradução de Inglês pela Estácio de Sá. Define-se como uma apaixonada por livros que a façam pensar e a tirem da sua zona de conforto, independente do gênero literário. Em entrevista dada ao blog Poltrona Literária ${ }^{12}$ em 2015, Juliana comenta sobre o sucesso do seu blog:

Demorou muito pra eu conseguir criar um blog, especialmente porque eu não encontrava nome legal que me agradasse, sério, demorou meses até eu me decidir por Nuvem Literária, e ainda assim, não comecei tão confiante. O Nuvem cresceu muito rápido e tomou proporções que eu nunca imaginei, como ter parcerias com editoras tão legais, e que elas próprias viessem me procurar, assim como autores que eu admiro, fazer amizades verdadeiras com outras(os) blogueiras a ponto de ir viajar para conhecêlas(os), tudo isso foi muito inesperado e maravilhoso (CARVALHO, 2015).

No blog, a divisão em categorias ocorre por: Livros, Filmes e Séries, Cotidiano, Papelaria, Plantas e Bem Estar. Já no YouTube, as playlists são compostas por: Vídeos recentes, Vídeos essenciais, Na minha estante, Book Hauls e Unboxings, Minhas leituras, Papelaria, Organização, TAGs e Listas, Livros por editoras e gêneros, Vlogs.

As resenhas no blog não têm uma periodicidade certa, às vezes são 5, 7 ou 10 dias. Além disso, no ano de 2018 houve um período maior sem publicação de resenhas, no dia 24 de maio e depois somente no dia 24 de agosto falando justamente "Sobre voltar a escrever em blog", publicação que teve vários comentários de seguidores da blogueira. Já no canal do YouTube, a blogueira está mais presente, chegando a divulgar mais de 1 vídeo por semana.

Em ambos os canais, em diversos momentos, Juliana fala sobre livros que recebeu da Amazon e sobre o Clube de Livros da TAG. No dia 20 de novembro de 2018, escreveu uma resenha sobre a TAG, colocando na especificação "Livros Publi". Mostrando, assim, que a blogueira recebe para algumas divulgações. Com a Amazon isso também ocorre, ao receber suas caixas, ela mostra desde a abertura, além de ter uma página de indicações de leitura na Amazon. Em seu blog há uma aba específica para "anuncie". Em 2018,

\footnotetext{
${ }^{11}$ Dados de março de 2020.

${ }^{12}$ Disponível em <http://lepoltronaliteraria.blogspot.com/2015/03/entrevistando-booktubers-1.html>.
} 
a blogueira criou o clube de livros "Nuvem Literária", com planos mensais e semestrais, que consiste num grupo de leitores que recebem leituras todos os meses e podem então dialogar sobre o livro com os demais integrantes do clube, criando uma rede de leitores.

\section{2 UNIVERSO DOS BLOGS E VLOGS}

Rios e Mendes (2014) relatam que se estima que existam 200 milhões de blogs no mundo. Segundo a Revista Época (2010), que divulgou um estudo realizado sobre o ambiente da blogosfera, o Brasil é o $4^{\circ}$ país em número de blogs, ficando atrás de Estados Unidos, Reino Unido e Japão. 0 estudo traçou ainda um perfil do público do blog, constatando que 50,9\% dos usuários são mulheres e que 53,3\% do público tem idade entre 21 e 35 anos.

Em uma pesquisa realizada pela BigData Corp em 2017 (PROPMARK, 2017), foi constatado que "existem mais de 5,5 milhões de blogs no Brasil e esse grupo representa 55,36\% dos cerca de 10 milhões de sites ativos no país", mostrando, assim, como os blogs têm espaço no país. O estudo (PROPMARK, 2017) falou ainda sobre anúncios, ressaltando que " $82,7 \%$ da blogosfera brasileira contêm anúncios". Em relação à audiência dos blogs, o relatório destacou que menos de $1 \%$ dos blogs recebem mais de meio milhão de acessos por mês, 96,5\% dos blogs são pequenos e computam, em média, dez mil visitas mensais (PROPMARK, 2017). Ainda, segundo a empresa (PROPMARK, 2017), entre as principais temáticas retratadas pelos blogs estão moda $(1,81 \%)$, tecnologia $(1,76 \%)$, cultura $(1,60 \%)$, política $(1,30 \%)$, esportes $(1,24 \%)$, viagem $(1,19 \%)$, entretenimento $(1,12 \%)$, beleza $(0,67 \%)$, games $(0,38 \%)$ e humor $(0,35 \%)$.

Ao tratar sobre o público do vlog, Alves e Silva (2018) destacam que o principal público são os jovens entre 13 e 24 anos, sendo que eles assistem em média 11,3 horas de vídeos por semana. Para os autores isto se deve, principalmente, pelo fato de a maioria dos vlogueiros serem jovens, sendo assim uma "conversa de jovem para jovem" (ALVES; SILVA, 2018, p. 44). Os autores destacam ainda que, por serem da era digital e cibernética, os jovens "não conseguem imaginar um mundo sem a convergência midiática e a internet" (ALVES; SILVA, 2018, p. 44), alterando, inclusive, os modos de leitura desses jovens que não mais somente absorvem a informação, mas querem interagir com esta, seja por meio de um comentário ou de uma curtida (ALVES; SILVA, 2018).

A partir dessa rede de contatos que já pode ser considerada uma rede social, como afirma Jeffman (2015), os blogueiros ganham espaço, autoridade e reconhecimento do público que os acompanha. 


\section{ANÁLISE DOS DADOS}

Para expor melhor os dados analisados, abaixo se apresenta um quadro com as categorizações de Jeffman (2015) - cultura do quarto, cultura de participação, cultura oral e estratégias de conexões, utilizadas nesta análise. Numeraram-se os vídeos de 1 a 10 e listaram-se quais características foram percebidas em cada um deles.

\section{Quadro 1 - Culturas e estratégias}

\begin{tabular}{|c|c|c|c|c|}
\hline Vídeo & $\begin{array}{c}\text { Cultura do } \\
\text { Quarto }\end{array}$ & $\begin{array}{c}\text { Cultura da } \\
\text { participação }\end{array}$ & Cultura oral & Estratégias de conexões \\
\hline 1 & $\mathrm{X}$ & $\mathrm{X}$ & $\mathrm{X}$ & Vídeo/Comentários \\
\hline 2 & $\mathrm{X}$ & $\mathrm{X}$ & $\mathrm{X}$ & Vídeo/Comentários \\
\hline 3 & $\mathrm{X}$ & $\mathrm{X}$ & $\mathrm{X}$ & Vídeo/Tag/Comentários \\
\hline 4 & $\mathrm{X}$ & $\mathrm{X}$ & $\mathrm{X}$ & Vídeo/Tag/Comentários \\
\hline 5 & $\mathrm{X}$ & $\mathrm{X}$ & $\mathrm{X}$ & Vídeo/Comentários \\
\hline 6 & $\mathrm{X}$ & $\mathrm{X}$ & $\mathrm{X}$ & Vídeo/Comentários \\
\hline 7 & $\mathrm{X}$ & $\mathrm{X}$ & $\mathrm{X}$ & Vídeo/Comentários \\
\hline 8 & $\mathrm{X}$ & $\mathrm{X}$ & $\mathrm{X}$ & Vídeo/Comentários \\
\hline 9 & $\mathrm{X}$ & $\mathrm{X}$ & $\mathrm{X}$ & Vídeo/Comentários \\
\hline 10 & $\mathrm{Não}$ & $\mathrm{X}$ & $\mathrm{X}$ & Vídeo/Comentários \\
\hline
\end{tabular}

\section{Fonte: Autoras (2018)}

Os dados acima apresentam de forma resumida as culturas e estratégias que se percebe nos vídeos analisados. Em quase todos os vídeos a blogueira está em um ambiente com livros em uma estante e objetos pessoais (fotos, agendas, mimos) a sua volta, acredita-se que se trata de seu quarto ou de um espaço em sua casa destinado à leitura. Sendo assim, verifica-se que o conceito apresentado por Jeffman (2015) como cultura do quarto, uma estratégia em que o vlogueiro traz mais autoridade para a sua fala e aproxima o público que o assiste, está presente nos vídeos da blogueira, com exceção do vlog, que foi filmado em um sebo.

Outra característica que se identifica nos vídeos é a chamada cultura da participação, relação que os leitores criam entre si compartilhando seus gostos e opiniões literárias, fato marcante nos comentários dos vídeos em que os seguidores conversam entre si, dão dicas de leituras e respondem aos questionamentos de outros seguidores. 
Percebe-se, ainda, que o vlog, ao trabalhar a cultura oral, resgata a história da leitura, circunstância destacada por Jeffmann (2015) ao dizer que o booktuber, ao utilizar a sua voz para relatar uma história, proporciona a socialização e desmistifica a leitura enquanto um ato solitário, tornando-a uma nova prática de leitura e de compartilhamento de opinião. Situação que se pode identificar nos vídeos da Ju Cirqueira, em que o leitor tem o ambiente propício para se sentir parte de uma rede de amigos, compartilhando saberes e opiniões sobre determinada leitura.

Em relação às estratégias de conexões, como evidenciado por Jeffman (2015), ao divulgar vídeos abordando o universo dos livros, a booktuber Ju Cirqueira constrói uma rede sólida de amigos por meio das suas respostas, das tags, dos comentários e do conteúdo do vídeo, formando, assim, uma rede social de leitores que se identificam com o conteúdo que ela produz e com a blogueira.

Percebe-se que além de utilizar a cultura oral, ao apresentar sua opinião sobre as obras em destaque, a blogueira faz uso do próprio livro - enquanto bem de consumo -, da rede de conexões do blog/vlog ao trazer tags e outras questões já abordadas por outros booktubers -, e da autoridade no assunto - por meio do ambiente em que se localiza (quarto dela com livros e objetos pessoais - indicando a cultura do quarto) e pelo conhecimento que demonstra em suas resenhas. Sendo assim, percebe-se que a blogueira faz o uso de várias estratégias de comunicação e de cultura nos vídeos.

Entende-se, assim, que a proximidade da blogueira com seus seguidores, além de ser um ato decorrente da fala, também ocorre por meio do livro enquanto objeto de consumo. A partir da exposição das obras literárias pela blogueira, seus seguidores desejam ter aquele bem em específico, para, assim, poderem compartilhar também suas opiniões e participarem ativamente do grupo.

Vê-se, assim, como Jeffman (2015) já destacou, que se criou uma rede de amigos entre a comunidade de booktubers e seus seguidores. A rede social - Youtube, Instagram, Facebook - tornou-se o local em que o seguidor pode dialogar livremente sobre os assuntos de seu interesse, informar-se e apresentar suas opiniões. O blogueiro faz parte da rotina de seus seguidores e, desta forma, torna-se um membro da rede de contatos, sendo que, em alguns casos, o relacionamento acaba tornando-se uma amizade.

\section{CONSIDERAÇÕES FINAIS}

A partir da análise dos dados, quantitativos e qualitativos dessa pesquisa, percebe-se que blogs e vlogs são ferramentas capazes de atingir um grande público e de fidelizar os seus seguidores. Os blogueiros reinventam-se e atingem mais público ao abrir espaço dos blogs tradicionais para as mídias sociais e o YouTube (que pode também ser considerado uma rede social). Os canais literários, em específico, 
utilizam-se de sua fala, de sua autoridade no assunto abordado e do próprio livro para alcançarem o público desejado, como se percebe por meio das categorizações de Jeffman (2015), que foram usadas nesta análise. Sendo assim, os vlogs literários, a nova versão dos blogs tradicionais, tornam-se um instrumento de interação e de pertencimento com o público seguidor.

Nos blogs e vlogs literários, diferente de outras categorias de blogs, não se busca a autopromoção, tais canais têm como intuito compartilhar experiências literárias e ser um espaço para discussão destas experiências, como já foi apresentado por Santos e colaboradores (2014), fato que pode ser percebido no vlog aqui estudado. A blogueira constantemente destaca para que os seus seguidores deixem nos comentários as suas experiências e propõe que o canal seja uma ferramenta de trocas, ou seja, um local em que leitores possam se encontrar, falar sobre os livros, o que acharam deles e indicar outros. Contexto que reforça a fala de Koch e Elias (2006), ao afirmarem que os leitores atualmente constroem e são construídos pelo texto. Sendo assim, a rede de booktubers proporciona um local de leitura ativa para os seus seguidores.

Percebe-se que o vlog literário tornou-se um canal de aproximação, de conexões, de amizades e de trocas. No canal da Ju Cirqueira, em diversos vídeos analisados, há a troca de experiências entre os seguidores, sugestões de leituras e, inclusive, participação de outros blogueiros literários por meio de comentários, sugestões e compartilhamento de Tags e ideias. Reforçando, assim, a característica de blogs/vlogs literários enquanto redes de comunicação/contatos/amizades.

Como já foi apresentado por Alves e Silva (2018), o principal público dos canais literários são os jovens, e a maioria dos booktubers também são jovens, fato que pode ser identificado no canal da Ju Cirqueira, pelos comentários dos seguidores, sendo uma característica que pode reforçar o pertencimento ao grupo da booktuber, por seus seguidores se identificarem tanto por sua fala como por sua idade.

Os vlogs literários se tornaram um canal de divulgação de uma forma de ler, uma leitura de mundo e uma interpretação em particular, a da blogueira. A blogueira pode apresentar uma nova concepção da leitura, a partir da sua experiência. No caso da blogueira Ju Cirqueira, ela não conta a história, só destaca os principais personagens e alguns pontos do livro, deixando para o leitor a sua percepção individual. Mas, ao apresentar alguns trechos da história, desperta nos seguidores o desejo de saber mais, de ler o livro. Entende-se a importância da leitura individual e compartilhada neste contexto, em que a blogueira indica a leitura, mas proporciona ao seguidor ter as suas experiências e percepções para então interagir com o grupo. Contribuindo, desta forma, com a percepção de um leitor vital, conceito apresentado por Assumção (2009), em que o seguidor interpretará a sua leitura de acordo com os seus conhecimentos de mundo e do contexto em que está inserido. 
Além disso, o livro é um objeto de consumo, e a blogueira, ao destacar pontos positivos e compartilhar suas experiências da obra, incita aos seus seguidores o desejo de ter aquele bem. Desta forma, ao estar em um ambiente rodeado de livros e ao estabelecer conexões, a blogueira cria laços com seus seguidores tendo como ponto inicial o livro, enquanto objeto material.

Sendo assim, a blogueira influencia na escolha dos livros de seus seguidores a partir do momento em que fala sobre determinado livro: mostrando sua capa, suas páginas, destacando personagens e dando ênfase em algumas questões que podem despertar o interesse no público leitor. Ao demonstrar autoridade no assunto, utiliza estratégias de aproximação, de empatia, e quando estabelece conexões e cria amizades por meio dos conteúdos divulgados, a blogueira está influenciando na escolha dos leitores.

A fidelização dos seguidores ocorre por meio de estratégias de comunicação e de conexões, além do uso das culturas de quarto, oral e de participação. No vlog analisado, a blogueira Ju Cirqueira utiliza em seus vídeos as estratégias destacadas e por meio das culturas de quarto e participação proporciona aos seus seguidores um sentimento de pertencimento a uma comunidade. Por meio das tags, comentários e dos próprios vídeos, a blogueira cria uma rede social com seus seguidores, formando, na realidade, uma rede de amigos. A oralidade, característica que é um destaque em vlogs, proporciona que os seguidores sintam-se mais próximos e participantes da história que a blogueira relata e desperta o desejo da compra, ou seja, fazendo com que o público tenha o interesse em adquirir o produto que a blogueira está divulgando.

Quanto às estratégias utilizadas pela blogueira para "vender" os livros, destaca-se o apelo visual, por meio da apresentação de características físicas do livro (como mapas, detalhes, cores) ensejando, desta forma, o desejo de ter o bem material. Sendo assim, a aquisição do livro impacta na cultura de participação, já que adquirindo o bem material, o seguidor poderá se sentir pertencendo a uma comunidade, compartilhando suas experiências e participando da comunidade de leitores que gostam ou não gostam de determinada obra. Visto que, até mesmo ao relatar questões que não gostou em um livro, o leitor estará fazendo parte de uma rede maior - a rede do booktuber. A partir da rede que booktubers estabelecem com seus seguidores, cria-se um corpo organizado e uma relação social mediada pelo computador.

Com relação à interação da blogueira Ju Cirqueira com seus seguidores, identifica-se que ocorre principalmente por meio dos comentários respondidos. Além disso, o próprio vídeo é uma forma de interação, sendo que a blogueira pede para que o público relate suas experiências e participe da discussão proposta, mostrando, assim, que espera a participação dos seguidores. Outra forma de interação que, inclusive, estabelece redes e conexões além de possibilitar interação são as Tags. Por meio das tags, os 
vídeos ficam categorizados sendo mais fácil identificar o assunto a ser tratado e, em muitos casos, são respostas às próprias perguntas dos seguidores.

Compreende-se que a pesquisa aqui proposta é relevante no contexto social em que estamos, sendo que mídias sociais e ferramentas da internet estão tendo cada vez mais espaço no mundo. Há vários conteúdos sobre o assunto no campo acadêmico, mas ainda é escasso o enfoque nas mídias sociais e canais de YouTube como estratégia de formação de leitores ou de influência de leitura, como é o caso do trabalho proposto aqui.

\section{REFERÊNCIAS}

ALVES, R. P. S.; SILVA, R. J. Vlogs e o incentivo à formação de leitores. Biblioteca Escolar em Revista, Ribeirão Preto, v. 6, n. 1, p. 43-63, 2018. Disponivel em: <https://www.revistas.usp.br/berev/article/ view/132613>. Acesso em: 06 jan. 2019.

ASSUMÇÃO, J. O leitor vital e o leitor-massa, em Ortega y Gasset. São Paulo: Global, 2009.

BALDISSERA, R. Estratégia, Comunicação e Relações Públicas. In: INTERCOM - Sociedade Brasileira de Estudos Interdisciplinares da Comunicação, XXIV Congresso Brasileiro da Comunicação, 2001, Campo Grande, MS. Anais do INTERCOM, Campo Grande: INTERCOM, 2001. Disponível em: <http://www. portcom.intercom.org.br/pdfs/8139078556980663261068270533436049754.pdf>. Acesso em: 04 fev. 2019.

BIRMAN, D. Literatura, imprensa e Internet: o autor, o leitor e a mediação que se quer invisível. Revista Língua \& Letras, Cascavel, v. 14, n. 27, 2013. Disponível em: <http://e-revista.unioeste.br/index.php/ linguaseletras/article/view/7122/6875>. Acesso em: 09 out. 2018.

CANCLINI, N. G. Leitores, espectadores e internautas. São Paulo: lluminuras, 2008. Disponível em: <https://d3nv1jy4u7zmsc.cloudfront.net/wp-content/uploads/itau_pdf/000726.pdf>. Acesso em: 05 out. 2018.

EGIERT, S. F.; MELLO, C. J. A. O papel do leitor e o gênero literário na recepção textual: contribuições de Tzvetan Todorov e Vincent Jouve. Revista Língua \& Letras, Cascavel, v. 14, n. 27, 2013. Disponível em: <http://e-revista.unioeste.br/index.php/linguaseletras/article/view/8659/6878>. Acesso em: 09 out. 2018. 
JEFFMAN, T. M. W. Literatura compartilhada: uma análise da cultura participativa, consumo e conexões dos Booktubers. Revista Brasileira de História da Mídia, São Paulo, v. 4, n. 2, p. 99-108, jul./dez. 2015. Disponivel em: <http://www.ojs.ufpi.br/index.php/rbhm/article/view/4166/2477>. Acesso em: 15 out. 2018.

KARHAWI, I. S. De blogueira à influenciadora: motivações, ethos e etapas profissionais na blogosfera de moda brasileira. 2018. 331 f. Tese (Doutorado) - Universidade de São Paulo. Escola de Comunicações e Artes. Programa de Pós-Graduação em Ciências da Comunicação, São Paulo, 2018. Disponível em: <http://www.teses.usp.br/teses/disponiveis/27/27152/tde-17092018-163855/pt-br.php>. Acesso em: 11 jan. 2019.

KOCH, I. V.; ELIAS, V. M. Ler e compreender: os sentidos do texto - 1ª ed. São Paulo: Contexto, 2006. Ler e compreender: os sentidos do texto - $2^{\text {a }}$ ed. São Paulo: Contexto, 2008.

KRUG, F. S. A importância da leitura na formação do leitor. Revista de Educação do IDEAU, Bagé, v. 10, n. 22, p. 1-13, jul./dez. 2015. Disponivel em: <https://www.ideau.com.br/getulio/restrito/upload/ revistasartigos/277_1.pdf >. Acesso em: 16 out. 2018.

LAJOLO, M. Do mundo da leitura para a leitura do mundo. São Paulo: Ática, 1993.

LIMA, M. V. B.; SILVA, M. V. A leitura dos contos de fada no ciberespaço: novas veredas para a busca dos significados da vida. In: IV FIPED - Fórum Internacional de Pedagogia, 2012, Parnaíba, PI. Anais do FIPED, Campina Grande: Realize Editora, 2012, p. 1-13. Disponível em: <http://editorarealize.com. br/revistas/fiped/trabalhos/fd7dee527244d528132d234eaa5922cb_1915.pdf>. Acesso em: 16 out. 2018

LOIS, L. Teoria e Prática da formação do leitor: leitura e literatura na sala de aula. Porto Alegre: Artmed, 2010.

MÁXIMO, M. E. O eu encena, o eu em rede: um estudo etnográfico dos blogs. Civitas - Revista de Ciências Sociais, Porto Alegre, v. 7, n. 2, p. 25-47, jul./dez. 2007. Disponível em: <http://www.redalyc. org/html/742/74270203/>. Acesso em: 26 out. 2018.

MOTTA, L. G. O Jogo entre Intencionalidades e Reconhecimentos: Pragmática Jornalística e Construção de Sentidos. Comunicação e Espaço Público, Brasília, ano 6, n¹/2, p. 7 -38, 2003. Disponível em: < http://repositorio.unb.br/handle/10482/12249>. Acesso em: 29 out. 2018. 
NASCIMENTO, A. J. Roger Chartier: contribuições e perspectivas gerais de suas obras. Revista Temática, João Pessoa, ano 14, n. 5, p. 188-205, mai. 2018. Disponivel em: <http://www.periodicos.ufpb.br/index. php/tematica/article/viewFile/39941/20076>. Acesso em: 05 out. 2018.

OLIVEIRA, C. et al. TIC's na educação: a utilização das Tecnologias da Informação e Comunicação na aprendizagem do aluno. Pedagogia em ação, Belo Horizonte, v. 7, n. 1, p. 75-95, 2015. Disponível em: <http://periodicos.pucminas.br/index.php/pedagogiacao/article/view/11019/8864>. Acesso em: 28 jan. 2019.

ORLANDI, E. P. Discurso e leitura - $3^{\mathrm{a}}$ ed. Campinas, SP: Editora da Universidade Estadual de Campinas, 1996.

PRIMO, A.; SMANIOTTO, A. Comunidades de blogs e espaços conversacionais. Prisma.com, Porto, n. 3, p 230-272, 2006. Disponivel em: <http://www.ufrgs.br/limc/PDFs/insanus.pdf >. Acesso em: 23 out. 2018.

PROPMARK. Mais de $\mathbf{8 0} \%$ da blogosfera brasileira exibe anúncios. 2017. Disponivel em: <http:// propmark.com.br/digital/mais-de-80-da-blogosfera-brasileira-exibe-anuncios>. Acesso em: 11 jan. 2019.

RECUERO, R. C. Weblogs, webrings e comunidades virtuais. V Seminário Internacional de Comunicação, 2003, Porto Alegre, RS. Anais do IV Seminário Internacional de Comunicação, Porto Alegre: PUC/ RS, 2003. p. 2-14. Disponivel em: <http://www.bocc.ubi.pt/pag/recuero-raquel-weblogs-webringscomunidades-virtuais.pdf >. Acesso em: 23 out. 2018.

REVISTA ÉPOCA. Brasil é o $4^{\circ}$ país do mundo em número de blogueiros. 2010. Disponível em: <http:// colunas.revistaepocanegocios.globo.com/tecneira/2010/07/29/brasil-e-0-4\%C2\%BA-pais-do-mundoem-numero-de-blogueiros/>. Acesso em: 22 out. 2018.

RIOS, G. A.; MENDES, Enicéia Gonçalves. Uso de blogs na educação: Breve panorama da produção científica na última década. Revista Eletrônica de Educação, São Paulo, v. 8, n. 2, p. 160-174, 2014. Disponivel em: <http://www.reveduc.ufscar.br/index.php/reveduc/article/view/746/331>. Acesso em: 22 out. 2018.

SANTOS, F. C. et al. Blogs literários: investigações sobre a audiência a partir da perspectiva dos usos e gratificações. Leituras do Jornalismo, Bauru, ano 1, n. 2, p. 101-114, jul./dez. 2014. Disponível 


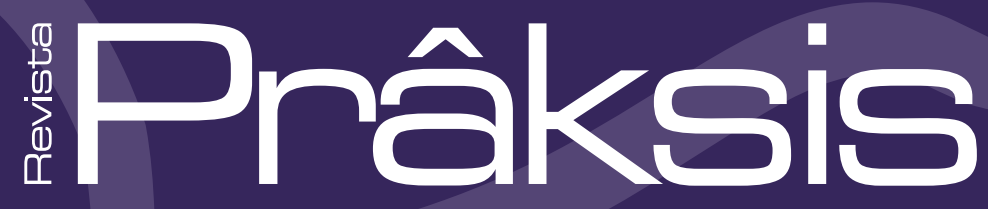

em: <https://www3.faac.unesp.br/leiturasdojornalismo/index.php/leiturasdojornalismo/article/ view/35/42>. Acesso em: 26 out. 2018.

SILVA, S. P. O blog e suas potencialidades para a prática da leitura. Revista Professare, Caçador, v. 4, n. 1, p. 111-116, 2015. Disponivel em: <https://periodicos.uniarp.edu.br/professare/article/ view/649/337>. Acesso em: 15 out. 2018.

SOUSA, P. J. et al. A blogosfera: perspectivas e desafios no campo da Ciência da Informação. Cadernos Bad I, Lisboa, v. I, p. 87-106, 2007. Disponível em: <https://www.bad.pt/publicacoes/index.php/ cadernos/article/view/783/782 >. Acesso em: 23 out. 2018. 